\title{
Fine-Scale Genetic Structure of Monilinia fructicola During Brown Rot Epidemics Within Individual Peach Tree Canopies
}

\author{
S. E. Everhart and H. Scherm
}

First and second authors: Department of Plant Pathology, University of Georgia, Athens, GA 30602.

Current address of first author: Department of Plant Pathology, University of Nebraska, Lincoln, NE 68583.

Accepted for publication 5 October 2014.

ABSTRACT

\begin{abstract}
Everhart, S. E., and Scherm, H. 2015. Fine-scale genetic structure of Monilinia fructicola during brown rot epidemics within individual peach tree canopies. Phytopathology 105:542-549.

The purpose of this study was to determine the fine-scale genetic structure of populations of the brown rot pathogen Monilinia fructicola within individual peach tree canopies to better understand within-tree plant pathogen diversity and to complement previous work on spatiotemporal development of brown rot disease at the canopy level. Across 3 years in a total of six trees, we monitored disease development, collected isolates from every $M$. fructicola symptom during the course of the season, and created high-resolution three-dimensional maps of all symptom and isolate locations within individual canopies using an electromagnetic digitizer. Each canopy population (65 to 173 isolates per tree) was characterized using a set of 13 microsatellite markers and analyzed for evidence of spatial genetic autocorrelation among isolates during the epidemic phase of the
\end{abstract}

Knowledge of pathogen dynamics and genetic structure can provide powerful insights into patterns and processes in plant pathogen populations, which are important for understanding the occurrence and spread of plant disease $(24,25)$. For brown rot of stone and pome fruits caused by fungi in the genus Monilinia, the disease cycle and epidemiology have been well-characterized (2). However, little is known about pathogen genetic variation or processes at the population level. Most studies on Monilinia spp. using molecular markers have focused on species delineations and/or quantifying broad-level (e.g., regional) population diversity $(11,15,18,22,23,32)$. On the other hand, studies with indirect genetic markers have provided some indication of population variation within individual orchards or tree canopies. For example, the within-tree frequency of $M$. fructicola isolates resistant to dicarboximide fungicide was used as an indirect marker to evaluate the spatial pattern and spread of strains in an orchard in New Zealand (6). Results showed different frequencies of resistant strains among tree canopies, but there was limited evidence for spread of resistant strains among canopies within a season and no evidence for spatial dependence in year-to-year frequency of resistant strains within the same tree. When vegetative compatibility groups (VCGs) were used as an indirect marker to differentiate M. fructicola isolates from diseased fruit in individual peach tree canopies in Georgia (30), isolates were found to be relatively diverse, yielding 23 different VCGs out of 100 isolates $(23.0 \%$ incompatibility) in one orchard and 37 VCGs out of 88 isolates (42.0\% incompatibility) in another. Most VCGs were represented

Corresponding author: H. Scherm; E-mail address: scherm@uga.edu

http://dx.doi.org/10.1094/PHYTO-03-14-0088-R

(C) 2015 The American Phytopathological Society disease. Results showed high genetic diversity (average $u h=0.529$ ) and high genotypic diversity (average $D=0.928$ ) within canopies. The percentage of unique multilocus genotypes within trees was greater for blossom blight isolates $(78.2 \%)$ than for fruit rot isolates $(51.3 \%)$, indicating a greater contribution of clonal reproduction during the preharvest epidemic. For fruit rot isolates, between 54.2 and $81.7 \%$ of isolates were contained in one to four dominant clonal genotypes per tree having at least 10 members. All six fruit rot populations showed positive and significant spatial genetic autocorrelation for distance classes between 0.37 and $1.48 \mathrm{~m}$. Despite high levels of within-tree pathogen diversity, the contribution of locally available inoculum combined with short-distance dispersal is likely the main factor generating clonal population foci and associated spatial genetic clustering within trees.

Additional keywords: disease aggregation, population genetics, Prunus persica, spatial analysis. by a single isolate, although one VCG representing a large percentage of isolates was obtained from a group of neighboring trees, suggesting short-distance spread among nearby trees from a common source of inoculum. In a similar study on nectarine in California, three trees from which $M$. fructicola isolates were obtained from fruit lesions harbored 36.8, 62.5, and 94.7\% unique VCGs, and only one VCG was common in the sample of 54 fruit rot isolates from the three canopies (33). These studies thus suggested considerable genetic variation at the canopy level, but also provided some evidence for genetic relatedness within and among trees. These results need to be confirmed with direct genetic markers and more explicit statistical approaches for determining fine-scale genetic structure and genetic clustering within canopies.

In a multiyear study on peach (Prunus persica), we monitored the within-canopy development of brown rot (caused by M. fructicola) during the course of the season and created high-resolution threedimensional maps of all symptoms within individual canopies using an electromagnetic digitizer (8). Explicit spatial analysis of the pattern of diseased fruit within canopies indicated the presence of significant disease aggregation early in the fruit rot epidemic, especially on early- and midseason peach cultivars. We hypothesized that these aggregation patterns were due to disease spread from within-tree sources of inoculum (such as previously infected blossoms or twig cankers) at a time in the season when orchard-wide inoculum was still limiting. We also obtained fungal isolates from each of the symptomatic fruit mapped in this study with the goal of developing a more complete insight into disease progression by analyzing genotypic data about the isolates associated with each symptom. Thus, the objective of the present study was to genotype the georeferenced isolates obtained previously from individual peach tree canopies using microsatellite markers (7), generate genetic similarity matrixes among all isolates within each 
tree, and conduct spatial autocorrelation analyses to quantify finescale genetic structure of $M$. fructicola isolates within canopies. The results will provide insight into genetic variation and dissemination of $M$. fructicola during fruit rot epidemics within peach tree canopies. In a broader context, the study may also serve as an example of a comprehensive characterization of fine-scale pathogen population structure within individual plants, which is applicable to other pathosystems and may be integrated into plant architectural models.

\section{MATERIALS AND METHODS}

Disease monitoring and symptom mapping. The study was conducted in a research orchard at the University of Georgia Horticulture Farm (Watkinsville, GA) from late March to early September in 2009, 2010, and 2011. The orchard was planted in 2000 and consisted of six peach cultivars of varying fruit maturity dates, arranged in replicate four-tree plots having within and across-row spacing of 4.8 and $6.1 \mathrm{~m}$, respectively. Across the 3 years, a total of 13 trees of the cultivars Sureprince (early-maturing), Redglobe (midseason), and O'Henry and Flameprince (both late-maturing) were included in detailed within-canopy disease monitoring and mapping (9). During the study, no fungicide applications to control brown rot were made, but foliar sprays of wettable sulfur were applied during the cover spray period to suppress peach scab (caused by Venturia carpophila). All other horticultural and pest management followed standard commercial practice (17). Trees were thinned relatively lightly to ensure a sufficient number of fruit per tree for within-tree mapping and spatial analysis.

Trees were monitored for symptoms and signs associated with $M$. fructicola infections (blossom blight, twig blight, twig cankers, green fruit rot, and brown rot of mature fruit) at 3- to 5-day intervals from bloom through final fruit swell and then every 1 to 4 days until fruit were tree-ripe. When a new symptom was detected, it was swabbed with a sterile cotton-tipped applicator to sample conidia, which was then stored at $4^{\circ} \mathrm{C}$ until pathogen isolation. A PVC tag was tied to the branch proximal to the point where the symptomatic element originated, and each label was marked with the date of symptom appearance and a unique identifying number. Thus, the spatial location and approximate date of appearance of each symptom and the associated fungal isolates were known.

High-resolution three-dimensional maps of the positions of symptom tags and of all fruit (symptomatic and asymptomatic) were created for each tree using an electromagnetic digitizer (FASTRAK 3Space, Polhemus, Colchester, VT) (31). The instrument creates a low-level electromagnetic field from an emitter positioned at the base of the tree and allows the user to position a sensor at the location of each point and record the corresponding $x, y$, and $z$ coordinates (8). Trees were digitized once (when fruit were tree-ripe) in 2009 and twice (at the beginning of the preharvest interval for all fruit and again at the end of the epidemic for all tagged symptoms) in 2010 and 2011. The resultant data set consisted of georeferenced coordinates for every fungal isolate within each tree and the date when it was obtained.

Pathogen culturing and genotyping. Single-spore isolations were performed for each sample. Conidia were dislodged from the cotton-tipped applicator by tapping it lightly along the edge of a petri dish with water agar. After $24 \mathrm{~h}$, germinating conidia were transferred individually onto potato dextrose agar. After 6 to 8 days of growth, aerial mycelium was harvested for DNA extraction with a DNeasy Plant Mini Kit (Qiagen, Valencia, CA).

Six of the 13 trees were selected for pathogen population analysis based on having 65 or more $M$. fructicola isolates that represented samples taken from every symptom that arose from blossom blight to fruit drop. This resulted in a total of $694 \mathrm{M}$. fructicola isolates (Table 1), 113 from blossoms and 581 from fruit. Purified DNA from each isolate was screened with 21 microsatellite markers, 16 from Everhart et al. (7) and five from Jänsch et al. (18). To enable indirect fluorescent labeling, primer pairs were synthesized with the addition of a CAG label (CAGTCGGGCGTCATCA added to the $5^{\prime}$-end of the shorter primer), and each polymerase chain reaction (PCR) included a HEX-labeled primer complementary to the CAGlabel $(1,10)$. PCR reactions were mixed using hot-start Taq (JumpStart Taq; Sigma-Aldrich, St. Louis, MO) following the manufacturer's reaction specifications, scaled to $12.5 \mu \mathrm{l}$, and modified to contain a 1:10 ratio of CAG-labeled primer to HEXlabeled primer. PCR conditions utilized a touchdown treatment where 20 cycles from 60 to $50.5^{\circ} \mathrm{C}$ enabled a range of primer melting temperatures to be met, followed by 15 cycles to increase the number of amplicons (4). Specifically, thermocycle conditions consisted of an initial treatment at $95^{\circ} \mathrm{C}$ for $2.5 \mathrm{~min}$; 20 cycles of $95^{\circ} \mathrm{C}$ for $20 \mathrm{~s}, 60^{\circ} \mathrm{C}$ for $20 \mathrm{~s}$ (decreased by $0.5^{\circ} \mathrm{C}$ for every cycle), and $72^{\circ} \mathrm{C}$ for $30 \mathrm{~s}$; followed by 15 cycles of $95^{\circ} \mathrm{C}$ for $20 \mathrm{~s}, 50^{\circ} \mathrm{C}$ for $20 \mathrm{~s}$, and $72^{\circ} \mathrm{C}$ for $30 \mathrm{~s}$. A 1:10 dilution of amplicons was denatured and analyzed using capillary electrophoresis (3730xl Analyzer; Applied Biosystems, Carlsbad, CA).

All 21 microsatellite markers showed amplification, but four markers were eliminated because they had $>10 \%$ null alleles that remained unresolved after rescreening. Another marker priming a dinucleotide repeat showed single-nucleotide polymorphisms, which did not allow accurate scoring of alleles, hence it was also eliminated. Thus, among the 21 markers applied in this study, 16 were suitable for analysis (SEA, SEC, SED, SEE, SEF, SEG, SEI, SEK, SEL, SEN, SEP, SEQ, and SER from Everhart et al. [7]; and CHMFc4, CHMFc5, and CHMFc12 from Jänsch et al. [18]). These markers were consistent and yielded fragment sizes as expected based on known repeat lengths, with $\leq 1.7 \%$ null alleles at each locus (average $0.43 \%$ ).

Population genetic variation. Two types of data sets were generated for population genetic analyses: one that contained all genotypes from each canopy population and the other that was a clonecorrected subset where every multilocus genotype was represented only once. Genetic diversity and population differentiation statistics were based on allele frequencies estimated from clone-corrected data, whereas genotypic diversity and spatial genetic autocorrelation were estimated from complete data.

Nei's genetic diversity, $h$, the probability that at a given locus, two randomly drawn alleles from the gene pool are identical (26), was calculated and subsequently weighted based on sample size to estimate unbiased haploid genetic diversity $(u h)$. Similarly, genotypic diversity, $D$, was calculated as an estimate of the probability that two individuals taken at random have different genotypes (27). Genetic $(u h)$ and genotypic $(D)$ diversity were calculated using GenAlEx 6.5 (28) and the R package poppr (19), respectively.

TABLE 1. Microsatellite variation at 13 polymorphic loci in six populations of Monilinia fructicola from individual peach tree canopies, where each population represents every fungal isolate obtained during an entire season (blossom blight to fruit drop)

\begin{tabular}{|c|c|c|c|c|c|}
\hline Population $^{\mathrm{a}}$ & $n$ & $\begin{array}{c}\text { Alleles per } \\
\text { locus }\end{array}$ & $\begin{array}{c}\text { Effective } \\
\text { alleles } \\
\text { per } \\
\text { locus }^{\text {b }}\end{array}$ & $\begin{array}{l}\text { Private } \\
\text { alleles }\end{array}$ & $\begin{array}{c}\text { Genetic } \\
\text { diversity } \\
\quad(u h)^{\mathrm{d}}\end{array}$ \\
\hline SP79-2010 & 65 & 3.62 & 2.02 & 2 & 0.475 \\
\hline RG7-2009 & 96 & 4.46 & 2.25 & 3 & 0.514 \\
\hline OH26-2009 & 173 & 4.69 & 1.95 & 4 & 0.442 \\
\hline OH26-2010 & 90 & 4.85 & 2.71 & 3 & 0.600 \\
\hline OH26-2011 & 127 & 5.39 & 2.65 & 6 & 0.562 \\
\hline FP45-2010 & 143 & 5.00 & 2.74 & 5 & 0.584 \\
\hline $\begin{array}{l}\text { Population-level } \\
\text { mean }\end{array}$ & 116 & 4.67 & 2.39 & 3.83 & 0.529 \\
\hline Pooled & 694 & 7.31 & 2.71 & - & 0.589 \\
\hline
\end{tabular}

a Populations denoted by tree cultivar (Sureprince $=\mathrm{SP}$, Redglobe $=\mathrm{RG}$, $\mathrm{O}^{\prime}$ Henry $=\mathrm{OH}$, and Flameprince $=\mathrm{FP}$ ), tree number, and year.

b Number of equally frequent alleles in a population with the equivalent level of genetic diversity.

c Number of alleles unique to the individual population.

d Unbiased haploid genetic diversity (26). 
Population differentiation. The index of association $\left(I_{A}\right)$, analysis of molecular variance (AMOVA), and spatial autocorrelation analyses were based on genetic distance. The use of a stepwise mutation model in calculating genetic distances was avoided because the emphasis of this study was to examine the clonal component of the population structure, which is best characterized using a binary distance measure. Thus, the difference at each locus between isolates yielded either a 0 (same allele) or 1 (different alleles). These distances were summed over loci to give a total genetic distance in a pairwise matrix between individuals. The variance among genetic distances within a canopy population was used to calculate $I_{A}$, where variance of pairwise distances is compared with the variance expected in the absence of linkage disequilibrium, estimated from 1,000 randomizations. Multilocus genotype evenness $\left(E_{5}\right)$ was estimated as the proportion of more abundant genotypes to rare genotypes (16). $I_{A}$ and $E_{5}$ were calculated in poppr, whereas AMOVA was carried out using GenAlEx 6.5.

Spatial autocorrelation. Spatial autocorrelation analyses of genetic distances were performed for populations within each tree canopy. Because we are interested in the effect of clonal dispersal within the canopy, data were not clone-corrected for this analysis. Both pairwise geometric (Euclidian) and pairwise squared genetic distance matrices are required as input for this analysis (28). Genetic distance matrices were calculated as described above, and Euclidian distance based on $x, y$, and $z$ coordinates for each isolate were calculated using Matlab R2011b (Mathworks, Natick, MA). The resulting matrices were used to assess each canopy population for spatial genetic autocorrelation using GenAlEx 6.5 software. Distance class bins of $0.37 \mathrm{~m}$ were chosen, showing a good compromise between spatial resolution and sample size within each class for all six trees. Furthermore, across the six trees, correlation analyses were performed to determine the degree of association between the magnitude of the spatial genetic autocorrelation coefficient over the first distance class $(0.37 \mathrm{~m})$ with disease incidence and with a measure of clonality, i.e., the average size of the dominant clonal genotypes per tree (those with 10 or more isolates per genotype).

\section{RESULTS}

Population genetic variation. A total of $694 \mathrm{M}$. fructicola isolates (113 from blighted blossoms and 581 from infected fruit) were obtained from symptomatic elements in the six trees and subsequently genotyped with 16 microsatellite markers. Three of these markers (SEC, SEF, and SEK) were hypervariable, hence results from the remaining 13 loci, where no locus had more than 11 alleles, are presented (Table 1). For each population, all 13 loci were polymorphic, with an average of 4.67 alleles per locus and 2.39 effective alleles per locus. These values did not vary much from tree to tree or within the pooled versus the mean data, indicating that the partitioning of genetic variation was similar at all scales and within each population; thus, comparisons among populations using frequency-based statistics would be meaningful. The number of private alleles for each population (alleles unique to that population) varied, where the tree with the fewest isolates (SP 79-2010; $n=65$ ) had the fewest private alleles (2) and trees with more than 100 isolates $(\mathrm{OH} 26-$ 2009, -2011, and FP 45-2010) had the most private alleles (4, 6, and 5, respectively). Unbiased haploid genetic diversity $(u h)$ in each tree ranged from 0.442 to 0.600 , with $u h$ in the pooled population equal to 0.589 .

Distribution of multilocus genotypes. Within each tree there were between 29 and 71 multilocus haplotypes represented for a total of 264 haplotypes across the six trees, with an average of $51.5 \%$ being unique within each tree, i.e., represented only once (Table 2). Conversely, other multilocus genotypes that were recovered more than once from each tree fell into 11 to 21 clonal groups per tree (total of 88 clonal groups across all trees), with the largest clonal groups having between 10 and 37 members per tree (Fig. 1). There were six isolates per clonal haplotype on average, and the evenness of multilocus genotypes within each tree averaged 0.543 . As a function of both the number and frequency of genotypes, genotypic diversity $(D)$ ranged from 0.879 (RG 7-2009) to 0.962 (FP 45-2010), with an average of 0.928 across trees.

Subpopulations of isolates obtained in the spring from blighted blossoms and those later in the season from affected fruit were also characterized (Table 2). The number of isolates obtained from blighted blossoms was always smaller than that from fruit affected by preharvest brown rot, and in some cases there were too few blossom blight isolates to calculate separate subpopulation parameters (trees SP 79-2010, OH 26-2010, and FP 45-2010). Not surprisingly, fewer haplotypes were present within the blossom blight subpopulations (average 16) than in the fruit rot subpopulation (average 34). A higher percentage of the haplotypes were unique among the blossom blight subpopulation (average across trees $69.3 \%$ ) than the fruit rot subpopulation (average $47.7 \%$ ). Across the six trees there were 21 isolates obtained from

TABLE 2. Distribution of genotypes in six populations of Monilinia fructicola from individual peach tree canopies, where each population represents every fungal isolate obtained during an entire season (blossom blight to fruit drop)

\begin{tabular}{|c|c|c|c|c|c|c|c|c|}
\hline & \multicolumn{6}{|c|}{ Population $^{\mathrm{a}}$} & \multirow[b]{2}{*}{ Mean } & \multirow[b]{2}{*}{ Pooled } \\
\hline & SP79-2010 & RG7-2009 & OH26-2009 & OH26-2010 & OH26-2011 & FP45-2010 & & \\
\hline Number of isolates & 65 & 96 & 173 & 90 & 127 & 143 & 116 & 694 \\
\hline From blighted blossoms & 1 & 23 & 41 & 5 & 30 & 13 & 19 & 113 \\
\hline From affected fruit & 64 & 73 & 132 & 85 & 97 & 130 & 97 & 581 \\
\hline Genotypes & 29 & 37 & 50 & 35 & 71 & 56 & 46 & 264 \\
\hline From blighted blossoms & 1 & 21 & 25 & 5 & 30 & 13 & 16 & 94 \\
\hline From affected fruit & 28 & 19 & 35 & 32 & 44 & 45 & 34 & 191 \\
\hline Genotypic diversity $(D)^{\mathrm{b}}$ & 0.916 & 0.879 & 0.901 & 0.958 & 0.950 & 0.962 & 0.928 & 0.986 \\
\hline From blighted blossoms & - & 0.992 & 0.948 & - & 1.000 & - & 0.980 & 0.993 \\
\hline From affected fruit & 0.913 & 0.792 & 0.881 & 0.954 & 0.914 & 0.955 & 0.902 & 0.983 \\
\hline Genotypic evenness $\left(E_{5}\right)^{\mathrm{c}}$ & 0.566 & 0.423 & 0.457 & 0.750 & 0.421 & 0.643 & 0.543 & 0.486 \\
\hline From blighted blossoms & - & 0.959 & 0.694 & 1.000 & 1.000 & 1.000 & 0.931 & 0.755 \\
\hline From affected fruit & 0.570 & 0.497 & 0.517 & 0.761 & 0.450 & 0.672 & 0.578 & 0.543 \\
\hline Index of association $\left(I_{A}\right)^{\mathrm{d}}$ & $1.724 *$ & $0.947 *$ & $0.633^{*}$ & $0.455^{*}$ & $0.227 *$ & $0.502 *$ & 0.748 & $0.227 *$ \\
\hline From blighted blossoms & - & $1.182 *$ & $0.392 *$ & - & 0.132 & - & 0.569 & $0.319 *$ \\
\hline From affected fruit & $1.760 *$ & $0.893^{*}$ & $0.803^{*}$ & $0.459 *$ & $0.466^{*}$ & $0.504^{*}$ & 0.814 & $0.254 *$ \\
\hline
\end{tabular}

${ }^{\text {a }}$ Populations denoted by tree cultivar (Sureprince $=$ SP, Redglobe $=$ RG, O'Henry $=$ OH, and Flameprince $=$ FP), tree number, and year

${ }^{\mathrm{b}}$ Genotypic diversity $(D)$ is defined as the probability that two individuals taken at random have different genotypes (27).

${ }^{c}$ Genotypic evenness $\left(E_{5}\right)$ is the ratio of abundant to rarer genotypes (16).

d The index of association $\left(I_{A}\right)$ tests for linkage disequilibrium, where an asterisk indicates statistical significance compared with 1,000 randomizations. 
affected fruit that were from the same clonal haplotype group as a blossom blight isolate (data not shown).

Based on the magnitude and significance level of $I_{A}$, significant linkage among loci was detected within each tree population and within pooled data, rejecting the null hypothesis of random mating. In two-thirds of cases $I_{A}$ was lower for the blossom blight subpopulations than the fruit rot subpopulations (Table 2). The null hypothesis of random mating was not rejected for the blossom blight subpopulation OH 26-2011, which was the only case in which this occurred.

Population differentiation. Differentiation among populations within tree canopies was tested using AMOVA based on clonecorrected data. Results of this analysis determined that $3.3 \%$ of molecular variance was present among trees, whereas $96.7 \%$ was within trees $\left(\Phi_{P T}=0.033, P=0.001\right)$. Pairwise comparisons of variance in genetic distance revealed that more than half (8 of 15) of the comparisons showed no significant population differentiation (Table 3). Specifically, in all cases where trees monitored within the same year were compared (four cases in Table 3), no significant differences were observed. When the same tree, $\mathrm{OH} 26$, was monitored across years $(2009,2010$, and 2011), two of the three pairwise comparisons (from 2009 to 2010 and from 2010 to 2011) were not significant; the one significant comparison in this case was between 2009 and 2011 (Table 3). Interestingly, when the same comparison among populations was carried out for non-clonecorrected data, it showed that all populations were significantly different (data not shown).

In one tree (OH 26), the M. fructicola population was monitored in 2009, 2010, and 2011. The clone-corrected subpopulation of isolates from blossom blight symptoms and from fruit rot symptoms, as they would occur over time, were compared sequentially by AMOVA (Fig. 2). This showed no significant difference in the subpopulations from one phase to the next (i.e., blossom blight in one year to fruit rot in the same year, or fruit rot in one year to blossom blight in the next). The greatest difference was observed for fruit rot subpopulations that occurred across the greatest time span (2009 to
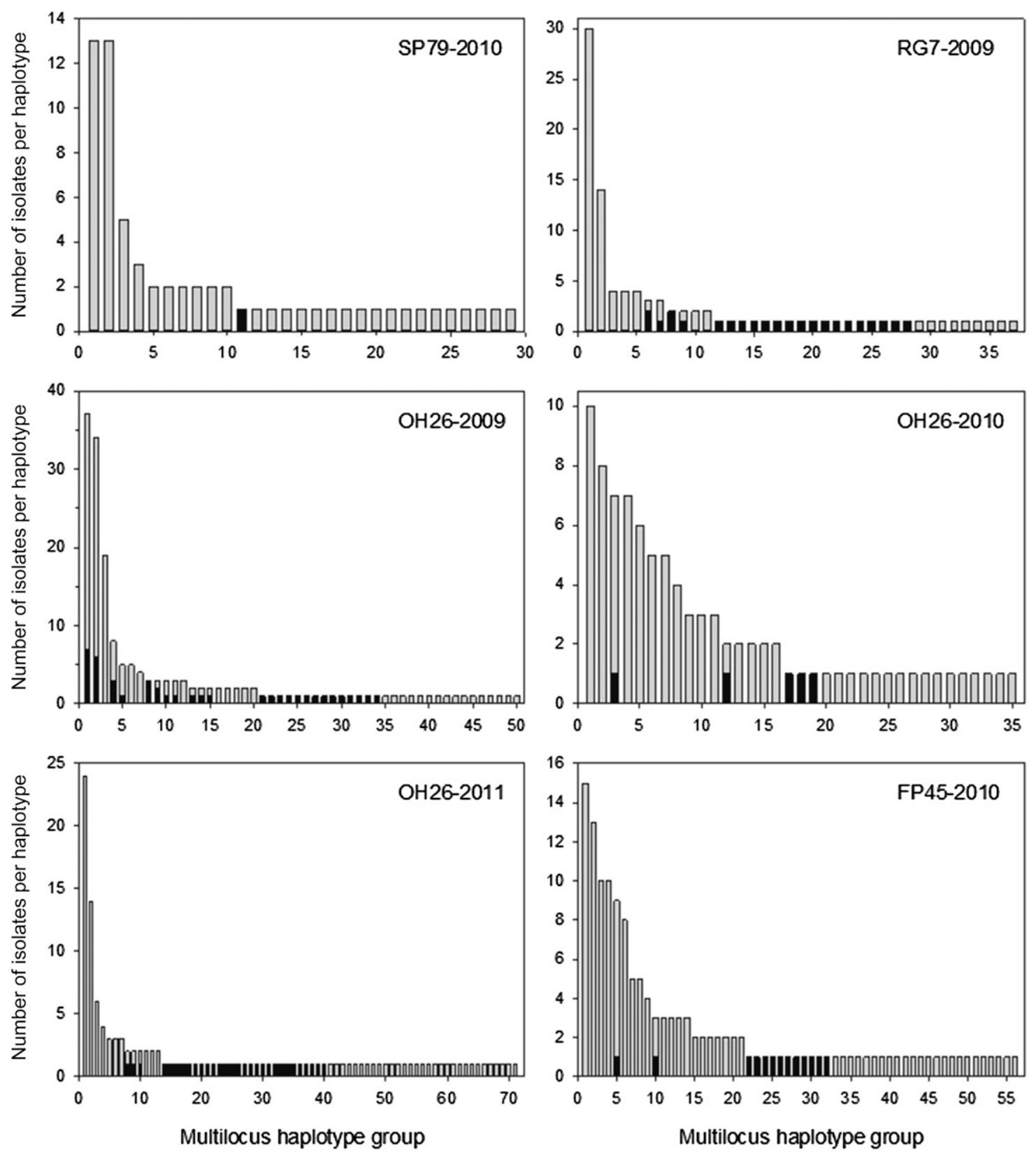

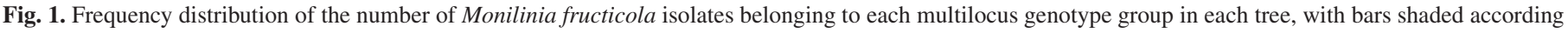
to the number of isolates belonging to the blossom blight subpopulation (black) or fruit rot subpopulation (gray). 
2011; $\left.\Phi_{P T}=0.074, P=0.001\right)$. The analysis was also performed using non-clone-corrected data to determine the level of relatedness that may be attributable to clonal haplotypes (Fig. 3). This showed significant difference between every subpopulation, with the exception of the blossom blight subpopulation to the fruit rot subpopulation obtained in 2010.

Spatial autocorrelation. Fine-scale spatial genetic structure was assessed with three-dimensional spatial autocorrelation analysis for each canopy population (Table 4, Figure 4). All populations showed positive and significant genetic autocorrelation up to the first (0.37 m; RG 7-2009 and FP 45-2010), second (0.74 m; OH 26-2011), third (1.11 m; SP 79-2010 and OH 26-2011), or fourth (1.48 m; OH 26-2009) distance class. Across the six trees, the magnitude of the autocorrelation coefficient at the first distance class $(0.37 \mathrm{~m})$ was significantly correlated with disease incidence $(r=0.854, P=0.030)$ and the average size of the largest clonal genotypes across the six trees $(r=0.849, P=0.032)$.

\section{DISCUSSION}

This is the first study to quantify the fine-scale population structure of a tree fruit pathogen within its host canopy in a spatial context. Genotyping all isolates from six peach trees showed that the genetic diversity of $M$. fructicola was typical of other ascomycete plant pathogens characterized using microsatellite markers $(5,13,33)$. The intermediate to high level of genotypic diversity and presence of 88 clonal genotypes among the total of 264 genotypes, yielding an average evenness in genotype abundance of $E_{5}=0.543$, is consistent with fungal pathogens that follow an "epidemic model" of population structure (24). Indeed, a combination of many unique multilocus genotypes and some clonal multilocus genotypes is typical of fungi with a mixed mode of reproduction, producing sexual ascospores in the spring, followed by successive waves of clonal reproduction during the season. The distribution in number of clones within each genotype showed that each tree had one to four dominant genotypes represented by $\geq 10$ clones, which constituted on average $35.4 \%$ of isolates in each population and $41.2 \%$ in each fruit rot subpopulation. The fact that large clonal groups did not dominate more in this pathosystem may be due to the fact that preharvest brown rot epidemics are oligocyclic, allowing only a limited number of epidemic cycles to occur during the 3- to 4-week fruit ripening phase within each tree.

Comparisons among the six populations showed that there were many genotypes within each canopy (average of 46), and that these differed among trees to the extent that $96.7 \%$ of molecular variance was within trees and only 13 clonal genotypes were represented in more than one tree. Pairwise comparison (including clones) showed that all trees had significantly differentiated populations, which may indicate that the majority of the population structure was due to individuals already established locally and serving as the predominant source of inoculum within the tree canopy. The importance of within-tree inoculum sources was further evidenced by significant spatial genetic autocorrelation among genotypes found within each tree. Not surprisingly, the populations with the strongest spatial genetic structure were those with the largest number of isolates belonging to a clonal genotype. For example OH 26-2009 had 137 isolates that belonged to one of 20 clonal genotypes; among these, most $(62.9 \%)$ were members of one of the three most represented clonal genotypes (37, 34, and 19 isolates in each; Fig. 1). These three genotype groups likely contributed to the majority of the genetic autocorrelation observed within the subpopulation up to $1.48 \mathrm{~m}$. This trend was evident in all trees, and the magnitude of the

TABLE 3. Pairwise comparison of clone-corrected molecular variance in six populations of Monilinia fructicola from individual peach tree canopies, where each population represents every fungal isolate obtained during an entire season (blossom blight to fruit drop) ${ }^{\mathrm{a}}$

\begin{tabular}{lccccc}
\hline & \multicolumn{5}{c}{ Population $^{\mathrm{b}}$} \\
\cline { 2 - 6 } Population & SP79-2010 & RG7-2009 & OH26-2009 & OH26-2010 & OH26-2011 \\
\hline SP79-2010 & - & & & & FP45-2010 \\
RG7-2009 & $0.084^{*}$ & - & - & & - \\
OH26-2009 & $0.082^{*}$ & 0.004 & 0.046 & - & -0.007 \\
OH26-2010 & 0.015 & $0.027^{*}$ & $0.039^{*}$ & $0.046^{*}$ & 0.002 \\
OH26-2011 & $0.044^{*}$ & $0.053^{*}$ & 0.048 & 0.001 & - \\
FP45-2010 & 0.017 & &
\end{tabular}

a Asterisks denote significant $\Phi_{P T}$ values compared with 1,000 randomizations.

b Populations denoted by tree cultivar (Sureprince $=\mathrm{SP}$, Redglobe $=\mathrm{RG}, \mathrm{O}^{\prime}$ Henry $=\mathrm{OH}$, and Flameprince $=\mathrm{FP}$ ), tree number, and year.

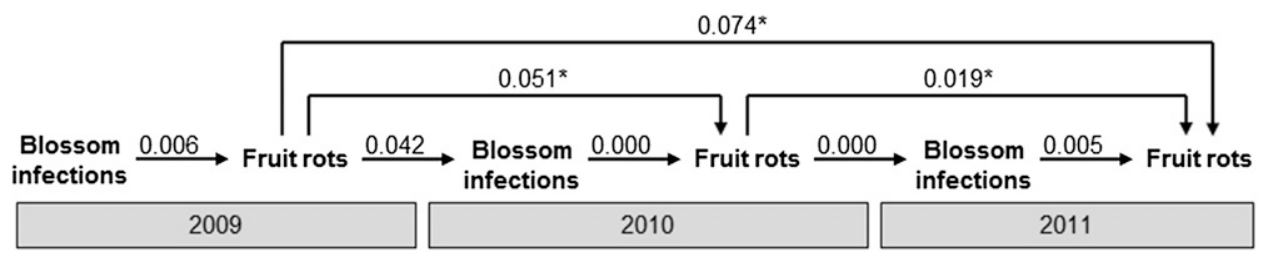

Fig. 2. Pairwise analysis of molecular variance in clone-corrected populations of Monilinia fructicola from the same peach tree canopy (OH26) across three successive growing seasons. Asterisks denote significant $\Phi_{P T}$ values compared with 1,000 randomizations.

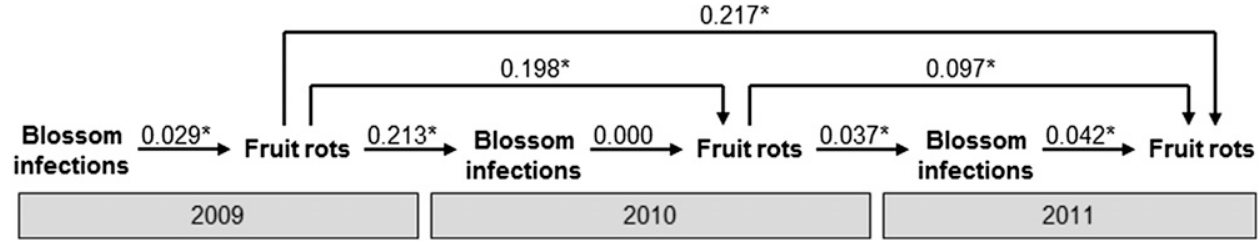

Fig. 3. Pairwise analysis of molecular variance in populations of Monilinia fructicola from the same peach tree canopy (OH26) across three successive growing seasons. Asterisks denote significant $\Phi_{P T}$ values compared with 1,000 randomizations. 
autocorrelation coefficient at the first distance class was significantly correlated with the average size of the largest clonal genotypes. Overall, the fact that all six populations showed positive and significant autocorrelation from the first and up to the fourth distance class (up to $1.48 \mathrm{~m}$ ) suggests a relatively consistent clonal dispersal distance from disease foci during the within-tree preharvest brown rot epidemic.

Our previous work examining the spatiotemporal aggregation of fruit rot symptoms during the disease epidemic showed that aggregation of diseased fruit was inversely related to disease incidence (9). In other words, the higher the disease incidence, the lower the aggregation of diseased fruit. This was likely the result of a saturation of disease foci within the canopy, such that the spatial pattern of disease became more random over time. In contrast, the spatial genetic autocorrelation analyses performed in the current study showed a significant positive correlation between disease incidence and the magnitude of the genetic autocorrelation coefficient. Thus, although high disease levels may obscure the spatial aggregation of disease, clustering of related genotypes and hence evidence of local spread is still apparent even at high disease levels when genetic structure is analyzed.

Our results can be interpreted in light of what is and is not known about the disease cycle of $M$. fructicola. The high uniqueness (low clonality) of isolates from blighted blossoms suggests that the source of primary inoculum infecting flowers is diverse, which could be different sources of asexual inoculum, genetically diverse sexual ascospores, or a combination of the two. Subsequently, some of these genotypes became a source of secondary inoculum because the same genotype was recovered from the fruit rot subpopulation in the same tree. However, this was a relatively rare occurrence, indicating that most were from a source other than within-canopy blossom blight (or that genetic recombination occurred between the blossom blight and fruit rot stages). Thus, external sources of secondary inoculum are contributing significantly to preharvest disease development. It is important to note, however, that the $M$. fructicola populations genotyped within these six trees represent only a subsample of all the trees with brown rot in the orchard. Connectivity between populations within individual trees in the same orchard was not fully explored in this study. It is likely that more shared genotypes would have been found between different populations if all trees were located within the same row or next to each other. Indeed, the two trees, OH 26 in 2010 and FP 45 in 2010 , sharing the greatest number of clonal genotypes found in more than one tree ( 7 of 13 ), are cultivars whose fruit mature within an overlapping period of $\approx 3$ weeks. None of the other trees were as close together in space and fruit maturation time, and fewer clonal genotypes were found within all other pairs of trees. Furthermore, only one genotype was recovered over more than
1 year, and in this case it was recovered from the same tree $(\mathrm{OH} 26)$ in 2009 and 2011.

Further insight into the orchard-level population structure was achieved by comparing the six populations after clone-correction, which showed that more than half of the pairwise comparisons were no longer significantly different. This suggests that there is lack of differentiation of the gene pool among isolates contributing to the epidemics within each tree. However, there was still year-to-year differentiation, in that all trees with significant differentiation were populations across different years. There were some exceptions to this rule, where populations within the same tree $(\mathrm{OH} 26)$ across different years were not differentiated. Further examining the subpopulations across years for $\mathrm{OH} 26$ in 2009, 2010, and 2011 showed that there was evidence of within-tree spatiotemporal population continuity. When examining the relationships for clonecorrected data, there were no significant population differences from the blossom blight subpopulation to the fruit rot subpopulation within the same year and from the fruit rot subpopulation to blossom blight subpopulation in the following year. With the exception of blossom blight to fruit rot subpopulations in 2010, all subpopulation comparisons were significantly different once the same analysis was performed including all clones, suggesting that composition of the population is significantly affected by presence of clones.

The high genotypic diversity obtained using microsatellite markers is consistent with the diversity of VCGs obtained for $M$. fructicola in peach and nectarine trees in previous studies $(30,33)$. Two such studies in California and Georgia showed that multiple VCGs were obtained from isolates within individual trees. From other studies it is known that a single VCG may represent multiple microsatellite genotypes (20). Both studies found that between 31.1 and $77.0 \%$ of fruit rot isolates were vegetatively compatible, also suggesting clonal dispersal within individual trees occurs. The results of these previous studies show that the high level of genotypic diversity obtained in the present study is an accurate representation of phenotypic variability.

The lack of population differentiation among all pairwise comparisons of populations within trees for clone-corrected data suggests that these trees share the same genetic pool, although reshuffling of genotypes may be occurring. Such reshuffling could occur via the parasexual cycle or sexual reproduction. Unfortunately, the primary mode of overwintering of $M$. fructicola in peach orchards in the southeastern United States is not well documented. In general, apothecial production within managed orchards in the region is considered rare, but is thought to occur more readily underneath wild plums (21). Another form of overwintering thought to play a more important role is asexual survival in twig cankers, peduncles, and fruit mummies in the tree (2). Our data showed significant linkage disequilibrium within nearly all populations.

TABLE 4. Three-dimensional spatial autocorrelation coefficients $(r)$ of genetic distances in six populations of Monilinia fructicola from individual peach tree canopies, where each population represents every fungal isolate obtained during the preharvest fruit rot phase ${ }^{\mathrm{a}}$

\begin{tabular}{|c|c|c|c|c|c|c|c|c|c|c|c|c|}
\hline \multirow{3}{*}{$\frac{\text { Interval }(\mathrm{m})^{\mathrm{b}}}{0.37}$} & \multicolumn{12}{|c|}{ Population $^{c}$} \\
\hline & \multicolumn{2}{|c|}{ SP79-2010 } & \multicolumn{2}{|c|}{ RG7-2009 } & \multicolumn{2}{|c|}{ OH26-2009 } & \multicolumn{2}{|c|}{ OH26-2010 } & \multicolumn{2}{|c|}{ OH26-2011 } & \multicolumn{2}{|c|}{ FP45-2010 } \\
\hline & $0.035^{*}$ & (157) & $0.132 *$ & (70) & $0.224 *$ & (114) & $0.112 *$ & (40) & $0.105^{*}$ & (76) & $0.036^{*}$ & $(451)$ \\
\hline 0.74 & $0.141^{*}$ & (145) & 0.023 & (208) & $0.182 *$ & (392) & $0.044 *$ & (141) & $0.050 *$ & (266) & 0.004 & (957) \\
\hline 1.48 & $-0.038^{*}$ & (295) & 0.029 & (446) & $0.042 *$ & (642) & 0.005 & (283) & 0.018 & (398) & 0.002 & (929) \\
\hline 1.85 & $-0.061 *$ & (310) & -0.018 & (447) & 0.012 & (680) & 0.014 & (296) & -0.001 & (367) & -0.004 & (991) \\
\hline 2.22 & $-0.050^{*}$ & (282) & 0.008 & (442) & 0.021 & (752) & 0.006 & (396) & 0.008 & (389) & 0.002 & (896) \\
\hline 3.33 & 0.038 & (104) & $0.076 *$ & (166) & $-0.052 *$ & (706) & -0.020 & (425) & -0.004 & (527) & -0.004 & $(687)$ \\
\hline 3.70 & -0.124 & (36) & 0.065 & $(120)$ & $-0.108^{*}$ & (511) & -0.015 & (413) & -0.006 & (453) & -0.007 & (281) \\
\hline
\end{tabular}

a Autocorrelation of genetic relatedness among isolates within spheres of increasing sizes (distance classes) within the same tree. Asterisks denote significant $r$ values compared with 1,000 randomizations.

b The number of comparisons for each distance class is shown in parenthesis.

${ }^{c}$ Populations denoted by tree cultivar (Sureprince $=\mathrm{SP}$, Redglobe $=\mathrm{RG}, \mathrm{O}^{\prime}$ Henry $=\mathrm{OH}$, and Flameprince $=$ FP), tree number, and year. 
Although studies in Europe have suggested that the observed significant linkage disequilibrium in $M$. fructicola populations point at asexual recombination as the primary mode of reproduction $(35,36)$, this does not explain the high genetic and genotypic diversity observed in our study. Despite the fact that apothecia were not observed in the orchard during the course of this study, it is possible that the significant linkage disequilibrium observed could result if $M$. fructicola is both homothallic and capable of outcrossing, which is thought to be the case in California (12). Additional studies to characterize both the mode of reproduction and regional population genetic structure of $M$. fructicola in the southeastern United States are warranted.

Collectively, the current work improves our understanding of brown rot disease epidemics and population genetics of $M$. fructicola within peach tree canopies. Further insight into the effect of plant architecture on within-canopy disease dynamics could be accomplished by integration of this data into a virtual plant model. Such functionalstructural plant models already exist for dynamically simulating the three-dimensional architecture of several plant species, including peach trees (34). Although some studies have integrated empirical elements of pathogen development and dispersal in order to model epidemics within virtual plants $(3,14,29)$, none have examined brown rot in peach trees and none have included knowledge from pathogen genotypes to inform dispersal modeling. Thus, integration of results from the present study into the virtual peach tree functional-structural plant modeling framework could enable further insight into how fruit spacing and peach tree structural architecture may influence brown rot epidemics.
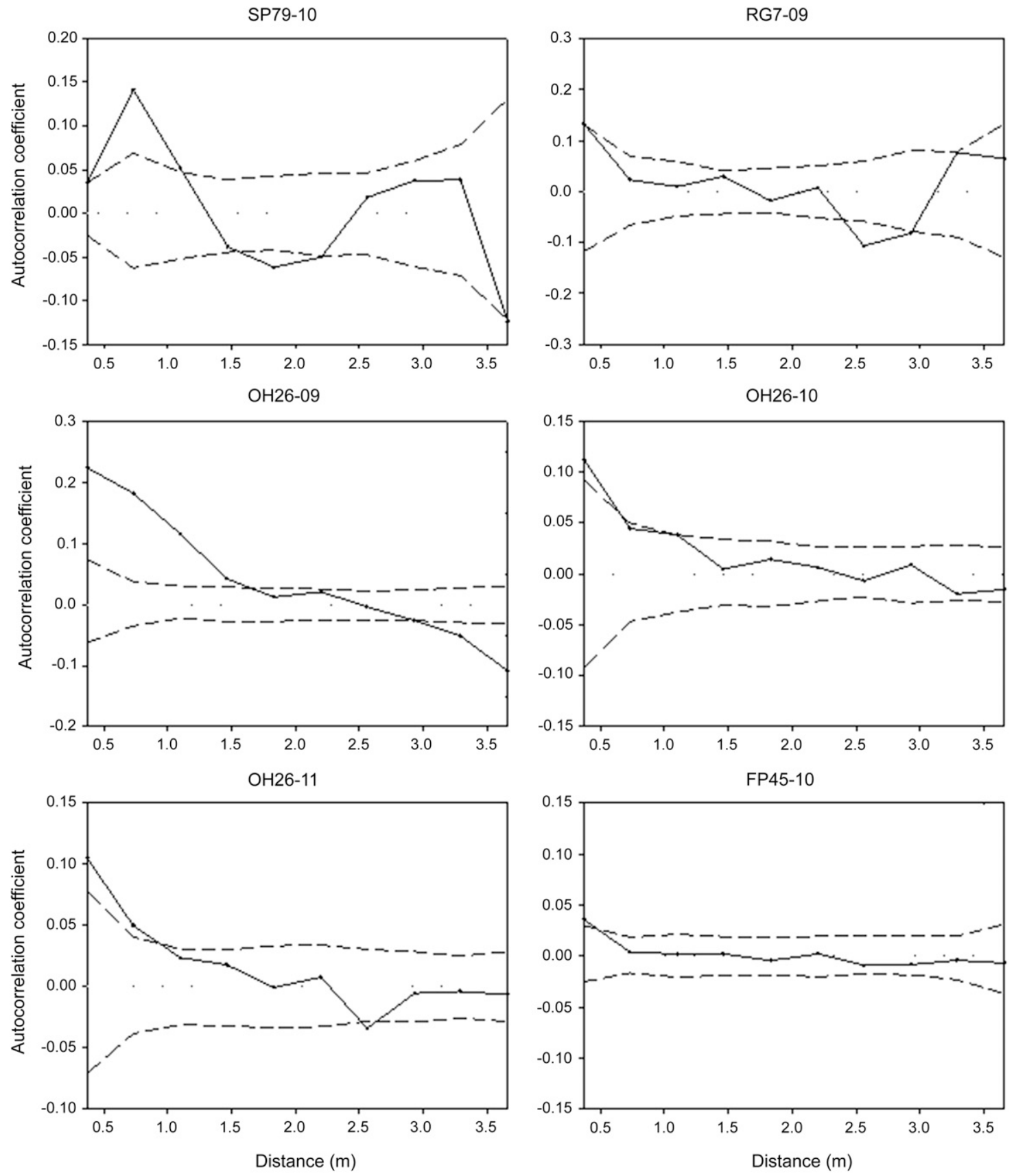

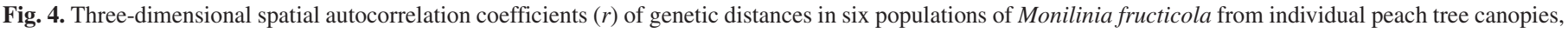

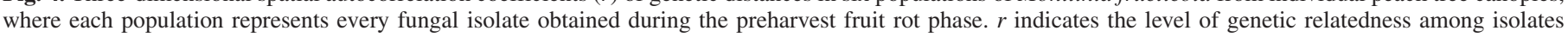

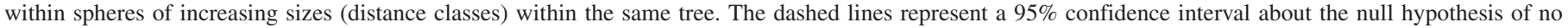
genetic autocorrelation. 


\section{ACKNOWLEDGMENTS}

We thank A. Savelle, S. Thomas, and L. Mehra for assistance in digitizing tree canopies, and D. Trapnell and M. Brewer for useful discussions. Funded in part by grant no. 2009-34103-19818 from the USDA Southern Region IPM Program. Additional financial support provided by The American Phytopathological Society's Tarleton Fellowship, a Sigma Xi Grant-in-Aid of Research, and a University of Georgia Dissertation Completion Award to S. E. Everhart.

\section{LITERATURE CITED}

1. Boutin-Ganache, I., Raposo, M., Raymond, M., and Deschepper, C. F. 2001. M13-tailed primers improve the readability and usability of microsatellite analyses performed with two different allele-sizing methods. Biotechniques 31:24-28.

2. Byrde, R. J. W., and Willetts, H. J. 1977. The Brown Rot Fungi of Fruit. Their Biology and Control. Pergamon, Oxford.

3. Calonnec, A., Cartolaro, P., Naulin, J.-M., Bailey, D., and Langlais, M. 2008. A host-pathogen simulation model: Powdery mildew of grapevine. Plant Pathol. 57:493-508.

4. Don, R. H., Cox, P. T., Wainwright, B. J., Baker, K., and Mattick, J. S. 1991. 'Touchdown' PCR to circumvent spurious priming during gene amplification. Nucleic Acids Res. 19:4008.

5. Douhan, G. W., Peever, T. L., and Murray, T. D. 2002. Multilocus population structure of Tapesia yallundae in Washington State. Mol. Ecol. 11: 2229-2239.

6. Elmer, P. A. G., Gaunt, R. E., and Frampton, C. M. 1998. Spatial and temporal characteristics of dicarboximide-resistant strains of Monilinia fructicola and brown rot incidence in stone fruit. Plant Pathol. 47:530-536.

7. Everhart, S. E., Askew, A., Seymour, L., Glenn, T. C., and Scherm, H. 2012. Spatial patterns of brown rot epidemics and development of microsatellite markers for analyzing fine-scale genetic structure of Monilinia fructicola populations within peach tree canopies. Plant Health Progress. doi:10.1094/PHP-2012-0723-04-RS.

8. Everhart, S. E., Askew, A., Seymour, L., Holb, I. J., and Scherm, H. 2011. Characterization of three-dimensional spatial aggregation and association patterns of brown rot symptoms within intensively mapped sour cherry trees. Ann. Bot. (Lond.) 108:1195-1202.

9. Everhart, S. E., Askew, A., Seymour, L., and Scherm, H. 2013. Spatiotemporal patterns of pre-harvest brown rot epidemics within individual peach tree canopies. Eur. J. Plant Pathol. 135:499-509.

10. Faircloth, B. C., Terhune, T. M., Schable, N. A., Glenn, T. C., Palmer, W. E., and Carroll, J. P. 2008. Ten microsatellite loci from Northern Bobwhite (Colinus virginianus). Conserv. Genet. 10:535-538.

11. Fan, J.-Y., Guo, L.-Y., Xu, J.-P., Luo, Y., and Michailides, T. J. 2010. Genetic diversity of populations of Monilinia fructicola (Fungi, Ascomycota, Helotiales) from China. J. Eukaryot. Microbiol. 57:206-212.

12. Free, S. J., Holtz, B. A., and Michailides, T. J. 1996. Mating behavior in field populations of Monilinia fructicola. Mycologia 88:208-211.

13. Frenkel, O., Portillo, I., Brewer, M. T., Péros, J. P., Cadle-Davidson, L., and Milgroom, M. G. 2012. Development of microsatellite markers from the transcriptome of Erysiphe necator for analysing population structure in North America and Europe. Plant Pathol. 61:106-119.

14. Garin, G., Fournier, C., and Andrieu, B., Houlès, V., and Robert, C., and Pradal, C. 2014. A modeling framework to simulate foliar fungal epidemics using functional-structural plant models. Ann. Bot. (Lond.) 114:795-812.

15. Gell, I., Larena, I., and Melgarejo, P. 2007. Genetic diversity in Monilinia laxa populations in peach orchards in Spain. J. Phytopathol. 155:549-556.

16. Grünwald, N. J., Goodwin, S. B., Milgroom, M. G., and Fry, W. E. 2003. Analysis of genotypic diversity data for populations of microorganisms. Phytopathology 93:738-746.
17. Horton, D., Brannen, P., Bellinger, B., Lockwood, D., and Ritchie, D. 2011. Southeastern Peach, Nectarine, and Plum Pest Management and Culture Guide. University of Georgia Cooperative Extension, Athens.

18. Jänsch, M., Frey, J. E., Hilber-Bodmer, M., Broggini, G. A. L., Weger, J., Schnabel, G., and Patocchi, A. 2012. SSR marker analysis of Monilinia fructicola from Swiss apricots suggests introduction of the pathogen from neighbouring countries and the United States. Plant Pathol. 61: 247-254.

19. Kamvar, Z. N., Tabima, J. F., and Grünwald, N. J. 2014. Poppr: An R package for genetic analysis of populations with clonal, partially clonal, and/or sexual reproduction. PeerJ 2:e281.

20. Kohn, L. M., Schaffer, M. R., Anderson, J. B., and Grünwald, N. J. 2008. Marker stability throughout 400 days of in vitro hyphal growth in the filamentous ascomycete, Sclerotinia sclerotiorum. Fungal Genet. Biol. 45: 613-617.

21. Landgraf, F. A., and Zehr, E. I. 1982. Inoculum sources for Monilinia fructicola in South Carolina peach orchards. Phytopathology 72:185-190.

22. Luo, C. X., and Schnabel, G. 2008. The cytochrome P450 lanosterol $14 \alpha$-demethylase gene is a demethylation inhibitor fungicide resistance determinant in Monilinia fructicola field isolates from Georgia. Appl. Environ. Microbiol. 74:359-366.

23. Ma, Z., Yoshimura, M. A., and Michailides, T. J. 2003. Identification and characterization of benzimidazole resistance in Monilinia fructicola from stone fruit orchards in California. Appl. Environ. Microbiol. 69: 7145-7152.

24. McDonald, B. A. 1997. The population genetics of fungi: Tools and techniques. Phytopathology 87:448-453.

25. McDonald, B. A., and McDermott, J. M. 1993. Population genetics of plant pathogenic fungi. Bioscience 43:311-319.

26. Nei, M. 1973. Analysis of gene diversity in subdivided populations. Proc. Natl. Acad. Sci. 70:3321-3323.

27. Nei, M. 1978. Estimation of average heterozygosity and genetic distance from a small number of individuals. Genetics 89:583-590.

28. Peakall, R., and Smouse, P. E. 2012. GENALEX 6.5: Genetic analysis in Excel. Population genetic software for teaching and research-an update. Bioinformatics 28:2537-2539.

29. Robert, C., Fournier, C., Andrieu, B., and Ney, B. 2008. Coupling a 3-D virtual wheat (Triticum aestivum) plant model with a Septoria tritici epidemic model (Septo 3-D): A new approach to investigate plantpathogen interactions linked to canopy architecture. Funct. Plant Biol. 35:997-1013.

30. Scherm, H., and Emery, K. M. 2002. Vegetative compatibility in populations of Monilinia fructicola from Georgia peach orchards. Acta Hortic. 592:725-727.

31. Sinoquet, H., Rivet, P., and Godin, C. 1997. Assessment of the threedimensional architecture of walnut trees using digitising. Silva Fenn. 31: 265-273.

32. Snyder, C. L., and Jones, A. 1999. Genetic variation between strains of Monilinia fructicola and Monilinia laxa isolated from cherries in Michigan. Can. J. Plant Pathol. 21:70-77.

33. Sonoda, R. M., Ogawa, J. M., and Manji, B. T. 1991. Population structure of Monilinia fructicola in Prunus persica var. nucipersica tree canopies. Mycol. Res. 95:893-895.

34. Sonohat, G., Sinoquet, H., Kulandaivelu, V., Combes, D., and Lescourret, F. 2006. Three-dimensional reconstruction of partially 3D-digitized peach tree canopies. Tree Physiol. 26:337-351.

35. Villarino, M., Larena, I., Martinez, F., Melgarejo, P., and De Cal, A. 2012. Analysis of genetic diversity in Monilinia fructicola from the Ebro Valley in Spain using ISSR and RAPD markers. Eur. J. Plant Pathol. 132: 511-524.

36. Villarino, M., Melgarejo, P., Usall, J., Segarra, J., and De Cal, A. 2010. Primary inoculum sources of Monilinia spp. in Spanish peach orchards and their relative importance in brown rot. Plant Dis. 94:1048-1054. 